Bull. Fac. Agric, Cairo Univ., 70:153-161(2019).

\title{
ECONOMIC EVALUATION FOR THE OPTIMUM SEEDING RATE FOR SOME BREAD WHEAT GENOTYPES
}

(Received: 5.5.2019)

\author{
By \\ Enas M. Mahmoud, Rania F. Mahmoud and Y. A. El- Gohary* \\ Center Laboratory for Design \&Stat. Analysis Research, and * Wheat Research Secncse, \\ Field Crop Research, Agricultural Research Center, Giza, Egypt.
}

\begin{abstract}
The present study aimed to evaluate the varieties and seeding rate yielding the highest productivity and net return for yield of the bread wheat crop. Analysis of variance and L.S.D Analysis approach was used to determine the effect of the experimental treatments applied in the experiment. Some criteria for the economic evaluation of agricultural experiments have also been calculated including net return and return of the invested pound. The results showed that when classifying the governorates of the Epypt according to the productivity of wheat crop for the average period (20142016) to nine production levels using the Duncan test. the governorates of the first. second. third. fourth and fifth rank were of high productivity. The results of the economic evaluation of the experiment showed that strain 1, strain 6 gave the highest productivity of feddan due to their superiority of the number of spikes and weight of 1000 kernels. Also. strain 1 gave the highest net return due to its high grain yield followed by strain 6 . The optimum seeding rate was 300 grains $/ \mathrm{m}^{2}$ where it achieved the highest productivity per feddan. The current study recommends to expand in producing new wheat genotypes such as strain 1 and strain 6 and using seeding rate of 300 grains $/ \mathrm{m}^{2}$ for its high productivity and economic efficiency.
\end{abstract}

Key words: Analysis of variance, Net return, Invested pound return.

$$
\begin{aligned}
& \text { التقييم الاقتصادي لمعدل التقاوي الأمثل لبعض التراكيب الوراثية من قمح الخبز } \\
& \text { إيناس ممدوح محمود - رانيا فكري محمود - ياسر أحمد الجوهري* } \\
& \text { المعمل المركزي لبحوث التصميم و التحليل الإحصائي ـ و* قسم بحوث القمح-معهد بحوث المحاصيل الحقلية } \\
& \text { - مركز البحوث الزراعيةـ الجيزة- مصر. }
\end{aligned}
$$

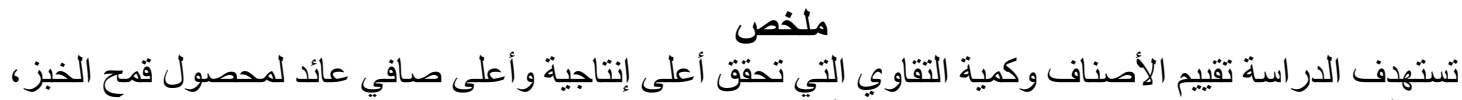

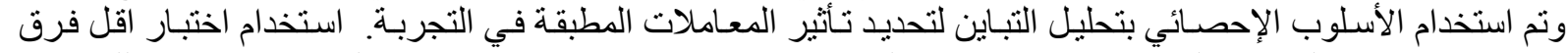

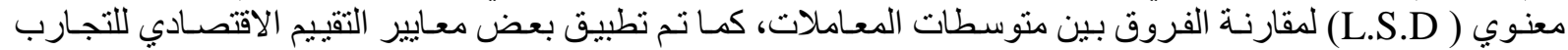

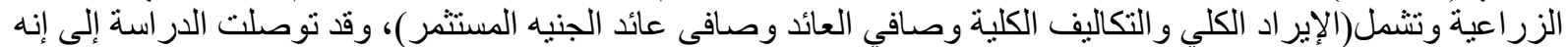

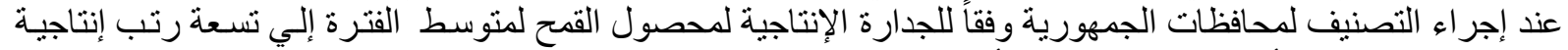

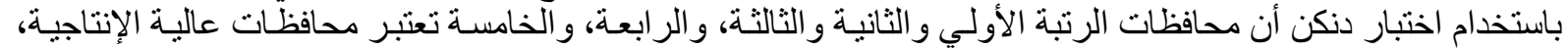

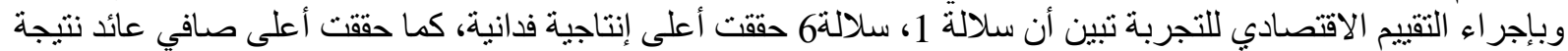

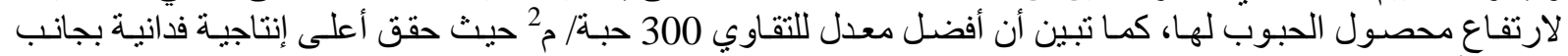

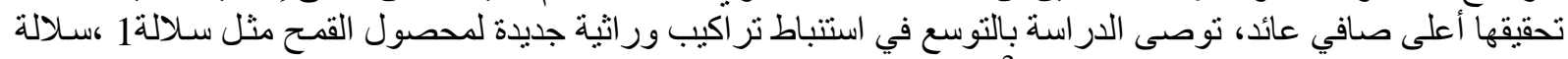

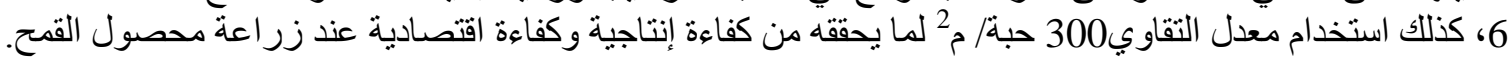


وتشمل(الإير اد الكلي و التكاليف الكلية وصافي العائد و عائد

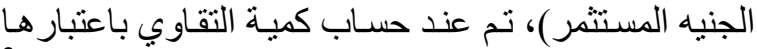

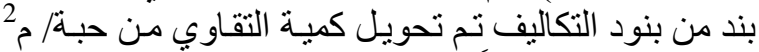

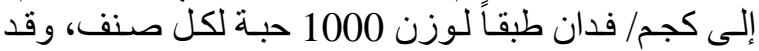

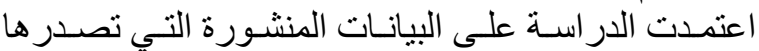

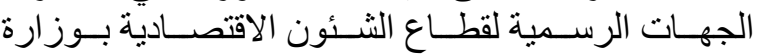

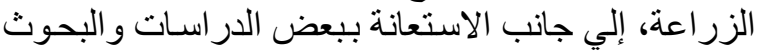

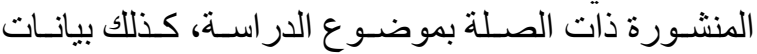
تجربتان حقليتان أقيمتا في محطة البحوث البرد الزر اعية بإيتاي

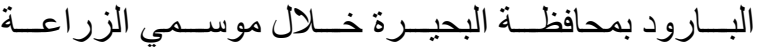
2014/15,2015/16

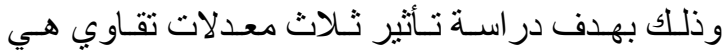

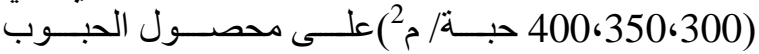

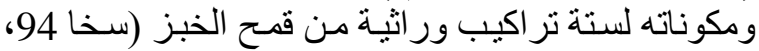

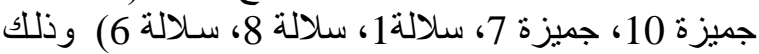
باستخدام تصميم القطع المنشقة (عبد العزيز 2004) مرة الترة

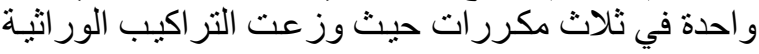
في القطع الرئيسية بينما وز عت معدلات التقاوي في القطع الثقية.

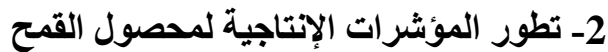

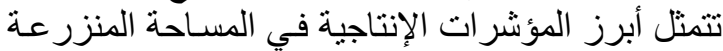

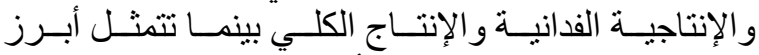

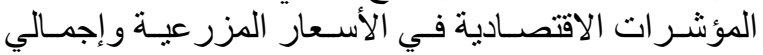

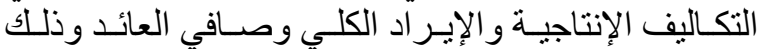
بالأسعار النقدية الجارية خلال الفترة (2016 -2000). -1-2 - المساحة المنزرعة النجارية يوضح جدول (1) أن مساحة القمح بلغت عام 2000 نحو 2.46 مليون فدان حيث أخذت هذه ألت المساحة في

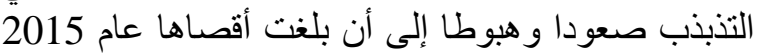
بنحو 3.47 مليون فدان بمتوسط قدره نحو 2000 مليون فدان

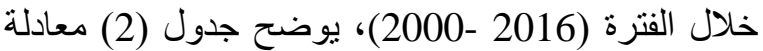
الاتجاه الزمني العام لتطور مساحة محصول القمح بالألف

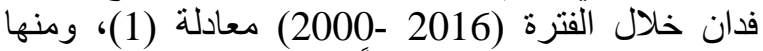
يتبين أن المساحة تنز ايد سنوياً بنحو 0.067 مليون فدانة

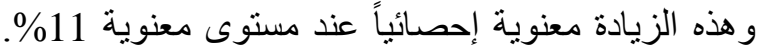

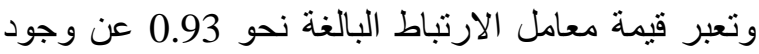

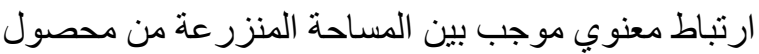

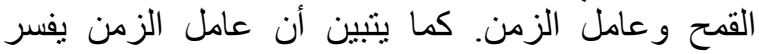

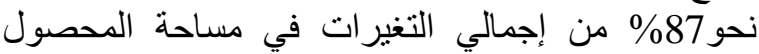
خلال فترة الدر اسة. 2-2-2 الإنتاجية الفدانية

يتبين من جدول (1) أن الإنتاجية الفدانية لمحصول

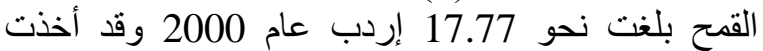
الإنتاجية في الارتفاع والانخفاض إلى أن بلغ بلغت أقصاها

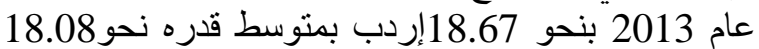

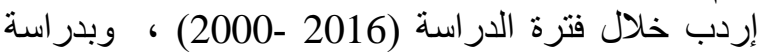
معادلة الاتجاه الزمني العام الترام لتطور الإنتاجية الفدانية لمحصول القمح بالطن خلال الفترة (2016- 2000). يتبين أن إنتاجية محصول القمح نتزايد سنويا بمقدار

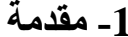

يعتبر محصول القهـح من محاصيل الحبوب الغذائيـة

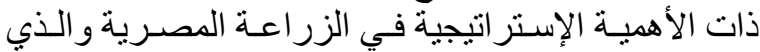
تضعه السياسات الاقتصـادية الزر اعية علي قالزائمسة أولوياتهـا

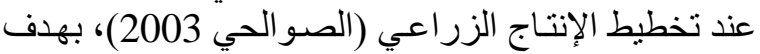

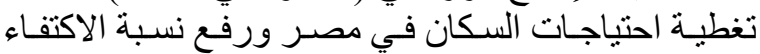

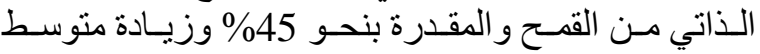
نصيب الفرد من المحصول و البالغ نحو 184 كجم/ كالبـ السنة

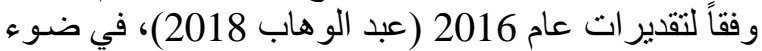

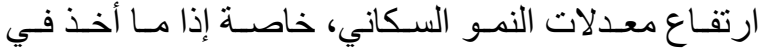

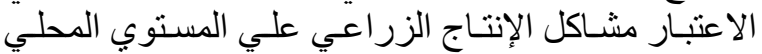

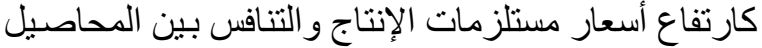

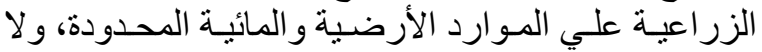

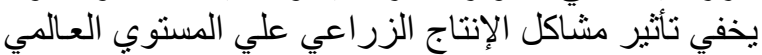

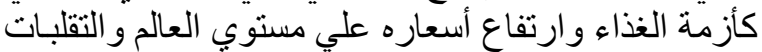

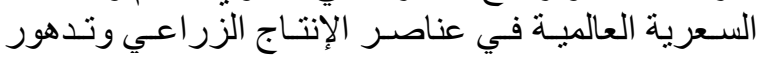

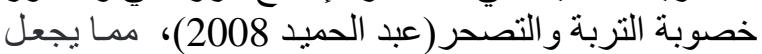

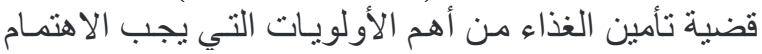

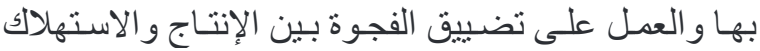

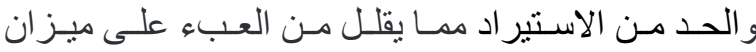

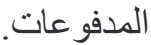
- 1-1 - 1 مشكلة الدراسة

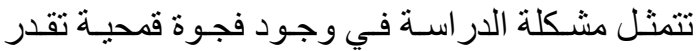
بنحو 10.06مليون طن بين الإنتاج المحلي الذي يليلغ نحو

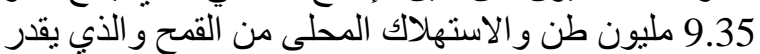

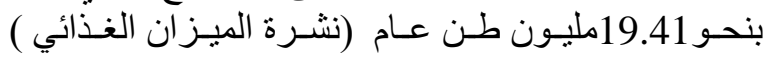

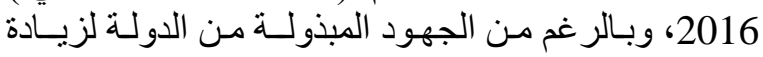

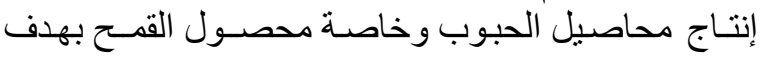
زيادة معدل الاكتفاء الذاتي وتضييق حجم الفجوة القمحية

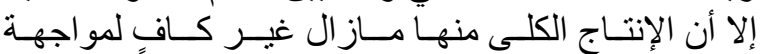

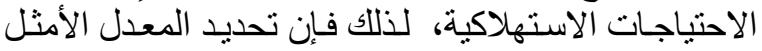

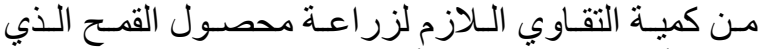
يعطي أعلى إنتاجية يعتبر أحد الحلول التي تساهم في زيادة التحادي

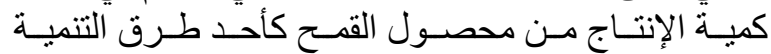
الزر اعية الر أسية. 2-1 - 2-1 أهداف الداراسة

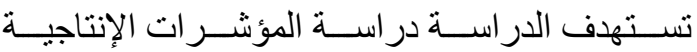

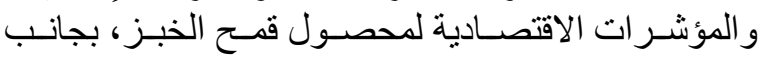

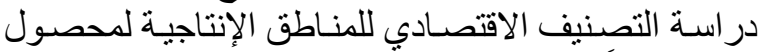

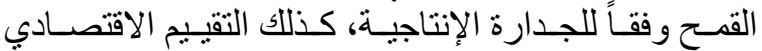

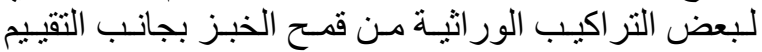

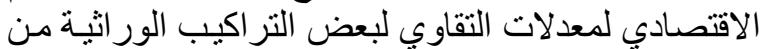

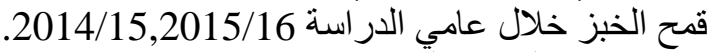

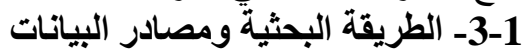

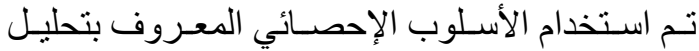

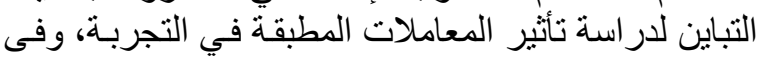

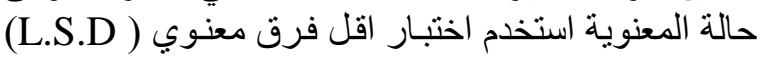

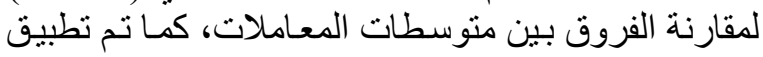

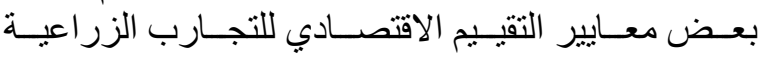


إجمـالي التغيـرات في السـعر المزرعي للمحصـول خـلال

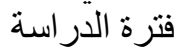

2-3-3 التكاليف الكلية

تعبر التكاليف عن أسعار مستلزمات الإنتاج اللازمـة

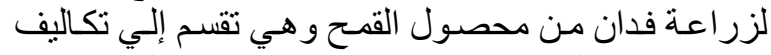
متغيرة وهي التي تتغير بتغير حجم الإنتاج و الي تكاليف

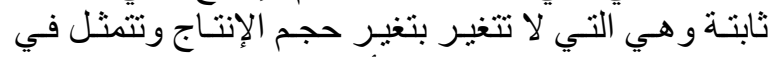

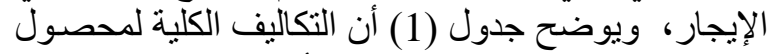

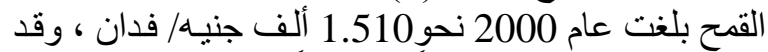
أخذت التكاليف اتجاها عاماً تصاعدياً إلى أن بلغت أقدان أقداها

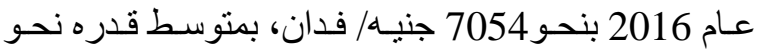

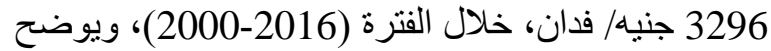

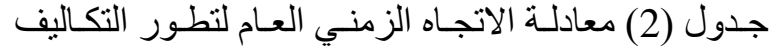

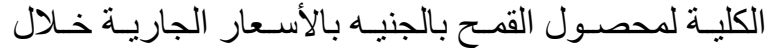

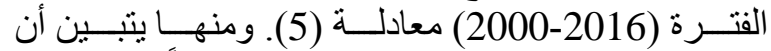

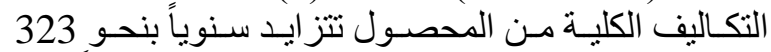

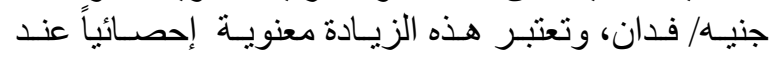

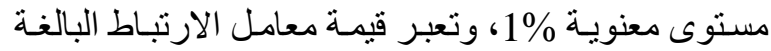

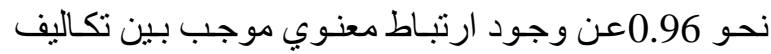

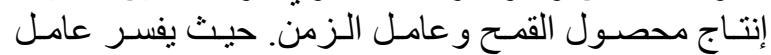
الزمن نحو\% 93 من إجمالي التغير ات في التكاليف الكلية

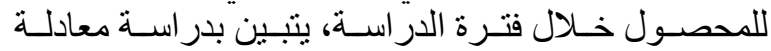

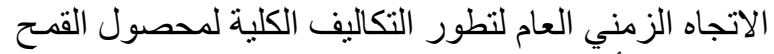

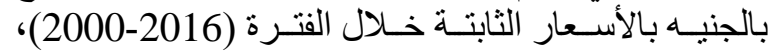

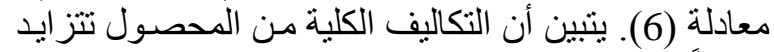

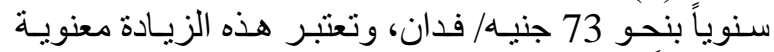

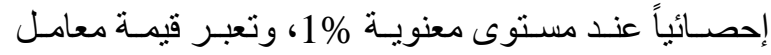
الارنباط البالغة نحو 0.91عن وجود ارتباط معنوي موجن معنب

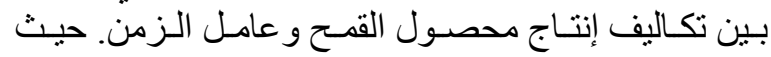

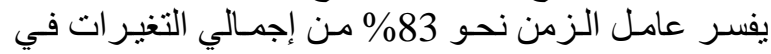
التكاليف الكلية للمحصول خلال فترة الدر استة. 3-3-3-الإيراد الكلي الكي

يوضح جدولّ (1) أن الإيراد الكير الكلي لمحصول القمح

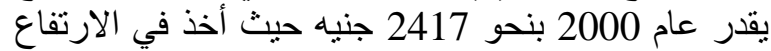

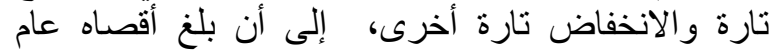

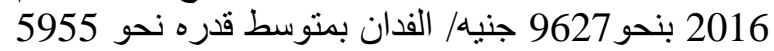

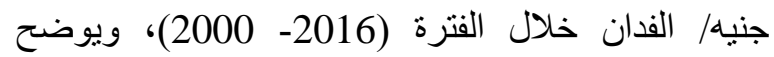
جدول (2) معادلة الاتجاه الزمني العام لنطور الإير اد الكئي

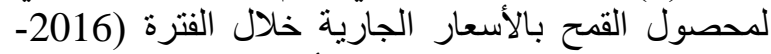
2000) معادلة (7) ومنها يتبين أن الإيراد الكلي ينز الإليد

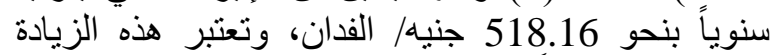

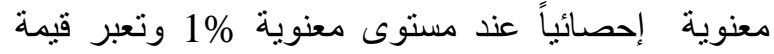

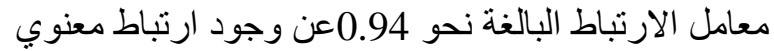

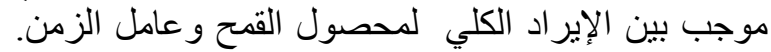

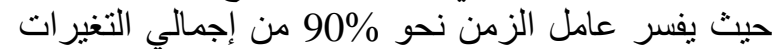

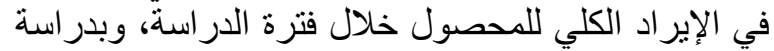

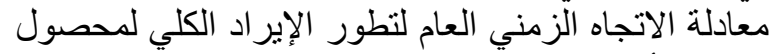

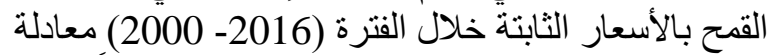

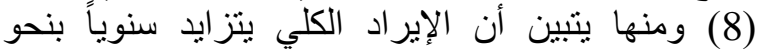
108.48 جنيه/الفدان، وتعتبر هذه الزيادة معنوية احصائيا
0.03إردب، وأن هذه الزيادة غير معنوية إحصائيا أي

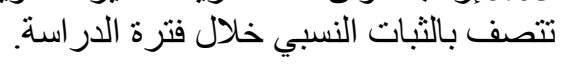

-3-2 - - - الإنتاج الكلى

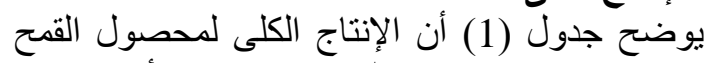

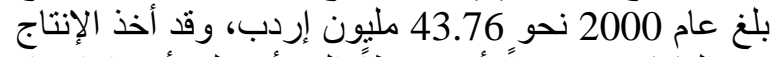

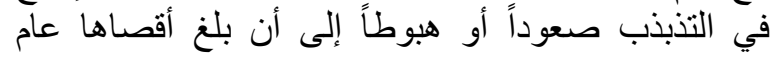

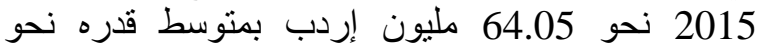

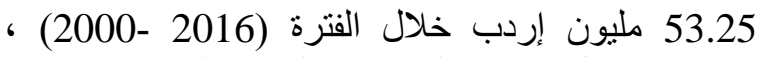
ويوضح جدول (2) معادلة الاتجاه الزمني العام (Draper)

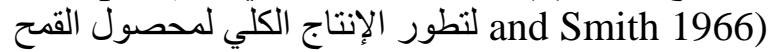

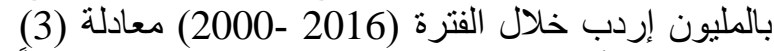

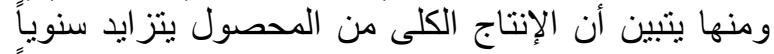

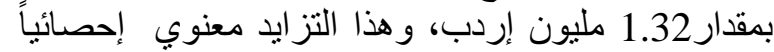

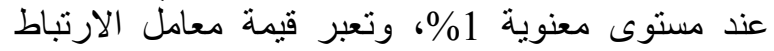

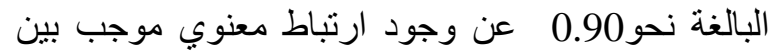

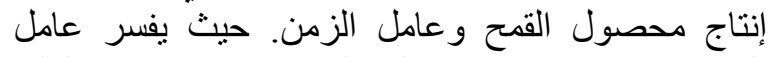
الزمن نحو 82\% من إجمالي التغيرات في الإنتاج الكلى اللمحصول خلال فترة الدر اسة. 3- 3وأشر ات الاقتصادية

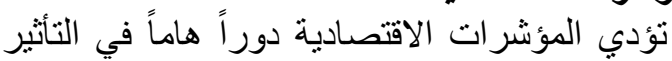

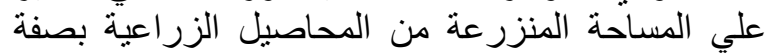

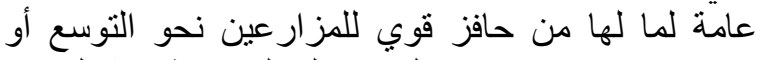

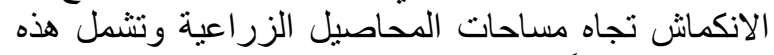

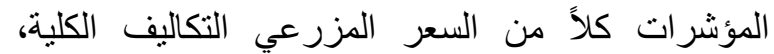

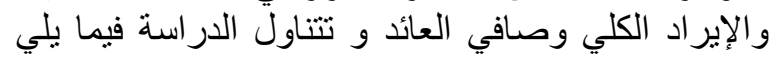

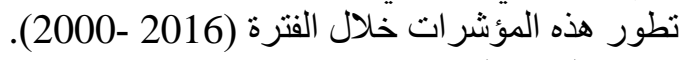
1-3 - السعر المزرعي

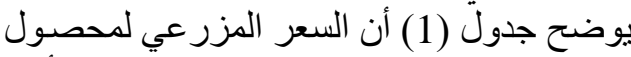

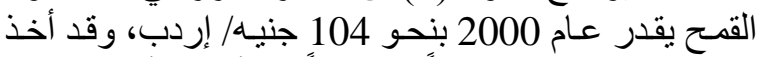

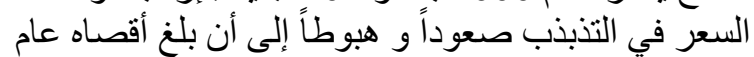

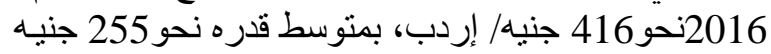

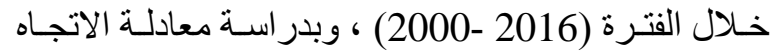

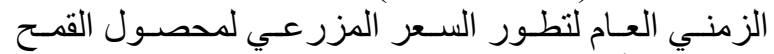

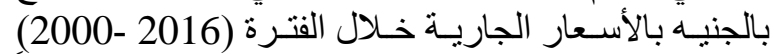

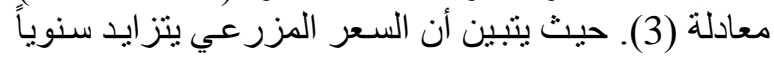

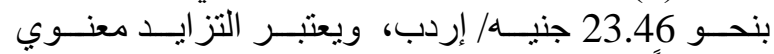

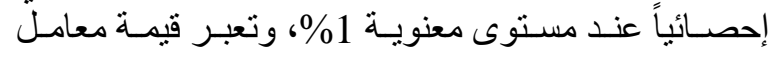

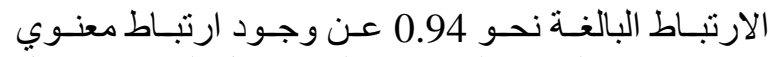

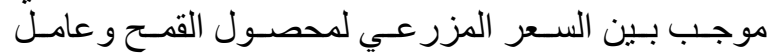

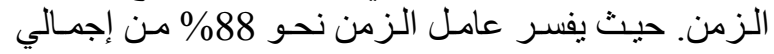

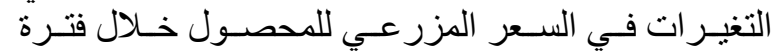

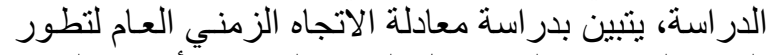

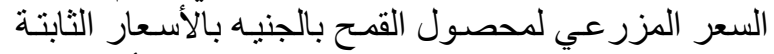

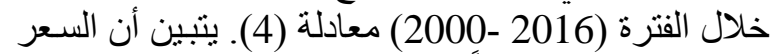

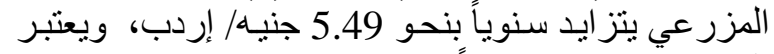

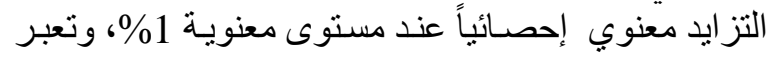

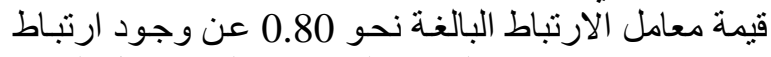

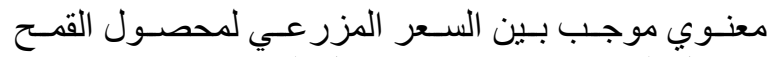

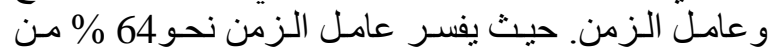




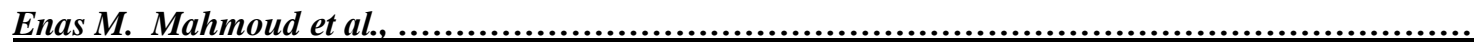

جدول (1) : المؤشرات الإتتاجية والاقتصادية لمحصول القمح خلال الفترة (2016-2000).

\begin{tabular}{|c|c|c|c|c|c|c|c|c|c|c|c|}
\hline جنيه/ فـان & جنيه/ فلان & التكلية & المنيه/ السعي & فنافيه & جنيه/ فالان & فلتيه/ & ألمنيه/ السعي & \multirow[t]{2}{*}{ أردب/ فالليون } & \multirow[t]{2}{*}{ بالإنتاجية } & \multirow[t]{2}{*}{ فالمليون } & \multirow[t]{2}{*}{ السنة } \\
\hline \multicolumn{4}{|c|}{ الأسعار الثابتة } & \multicolumn{4}{|c|}{ الأسعار الجارية } & & & & \\
\hline 907 & 2418 & 1510 & 104 & 907 & 2418 & 1510 & 104 & 43.76 & 17.77 & 2.46 & 2000 \\
\hline 884 & 2301 & 1385 & 95 & 972 & 2531 & 1523 & 105 & 41.697 & 17.81 & 2.34 & 2001 \\
\hline 779 & 2103 & 1355 & 94 & 896 & 2419 & 1558 & 108 & 44.165 & 18.02 & 2.45 & 2002 \\
\hline 1388 & 2975 & 1278 & 95 & 1666 & 3570 & 1534 & 114 & 45.631 & 18.21 & 2.51 & 2003 \\
\hline 1577 & 3175 & 1535 & 121 & 1956 & 3937 & 1904 & 150 & 47.852 & 18.37 & 2.61 & 2004 \\
\hline 1360 & 2924 & 1446 & 123 & 1863 & 4006 & 1981 & 168 & 54.273 & 18.18 & 2.99 & 2005 \\
\hline 1291 & 3075 & 1564 & 123 & 1769 & 4213 & 2143 & 169 & 55.162 & 18 & 3.06 & 2006 \\
\hline 1011 & 2407 & 1397 & 99 & 1769 & 4213 & 2444 & 173 & 49.193 & 18.12 & 2.72 & 2007 \\
\hline 2701 & 4348 & 1647 & 201 & 5159 & 8304 & 3145 & 383 & \begin{tabular}{|l|l|}
53.18 \\
\end{tabular} & 18.21 & 2.92 & 2008 \\
\hline 1147 & 2958 & 1811 & 127 & 2190 & 5649 & 3459 & 242 & \begin{tabular}{|l|}
56.82 \\
\end{tabular} & 18.06 & 3.15 & 2009 \\
\hline 1041 & 2977 & 1921 & 143 & 1977 & 5657 & 3650 & 272 & 47.793 & 15.92 & 3.00 & 2010 \\
\hline 1858 & 3805 & 1947 & 168 & 3884 & 7953 & 4069 & 352 & $\mathbf{5 5 . 8 0 3}$ & 18.3 & 3.05 & 2011 \\
\hline 1990 & 4011 & 1990 & 173 & 4358 & 8783 & 4358 & 378 & 58.636 & 18.55 & 3.16 & 2012 \\
\hline 1858 & 3949 & 2090 & 168 & 4274 & 9082 & 4808 & 387 & 63.068 & 18.67 & 3.38 & 2013 \\
\hline 1708 & 3932 & 2224 & 173 & 4047 & 9318 & 5271 & 411 & 61.865 & 18.23 & $\begin{array}{l}3.39 \\
\end{array}$ & 2014 \\
\hline 1609 & 3904 & 2297 & 169 & 3941 & 9564 & 5627 & 413 & 64.051 & 18.46 & 3.47 & 2015 \\
\hline 1009 & 3775 & 2766 & 163 & 2572 & 9627 & 7054 & 416 & 62.283 & 17.57 & $\mathbf{3 . 3 5}$ & 2016 \\
\hline
\end{tabular}

4- التصنيف الاقتصادي للمناطق الإتتاجية

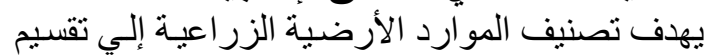

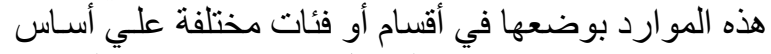

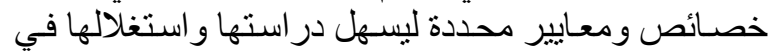

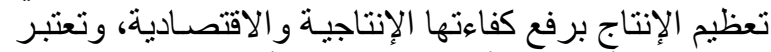

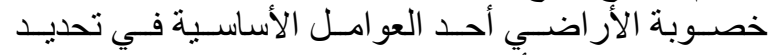

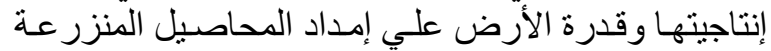

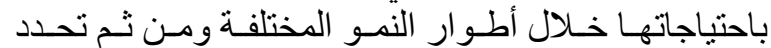

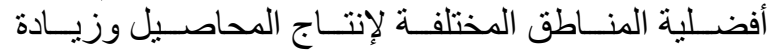

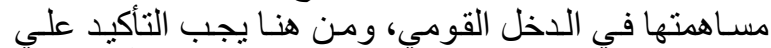

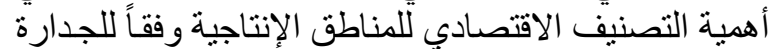

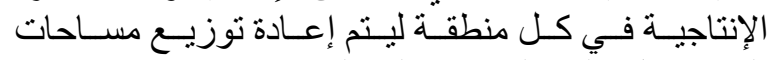

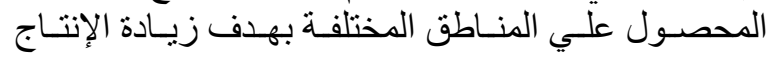

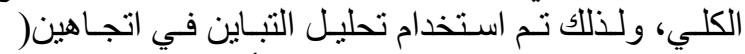

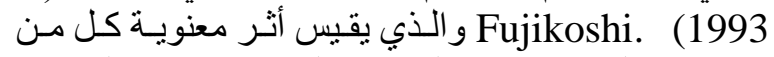

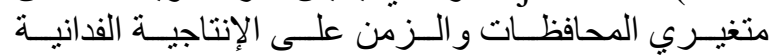

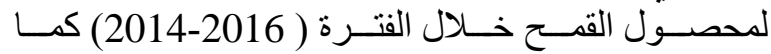

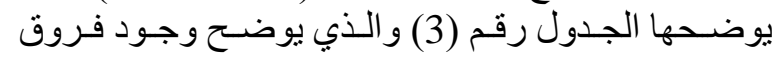

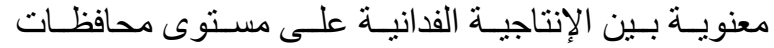
الجمهورية المختلفة.

وينت التصنيف وفقاً لطريقة أقل فرق معنوي. L.S.D

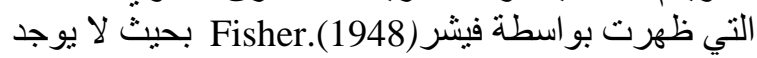

عند مستوى معنوية 1\%، وتعبر قيمة معامل الارتباط

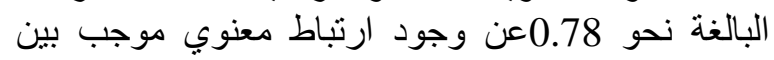

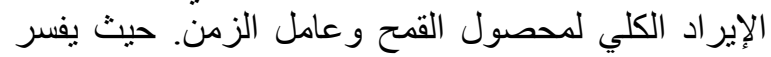
عامل الزمن نحو 62\% من إلجمالي التغيرات في الإلير الفير الكلي للمحصول خلال فترة الدراسة. 4-3-3-صافي العائد يوضح جدول (1) أن صافي عائد الفدان لمحصول

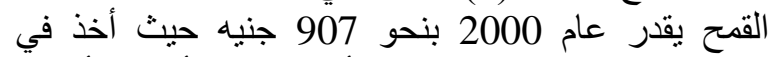
الارتفاع تارة والانخفاض تارة أخرى، إلى أن بلغ أقصأه

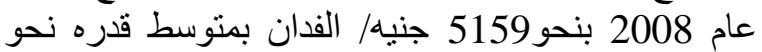

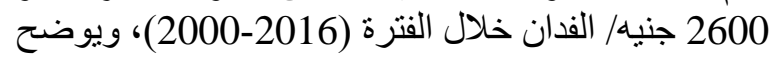
جدول (260) معادلة الاتجاه الزمني العام لتطور الفئرة صافي عائد

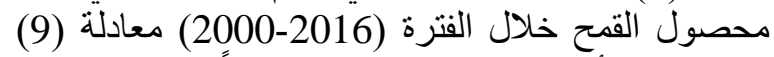
ومنها ينبين أن صافي العائد ينز ايد سنوياً بنحو 202.32

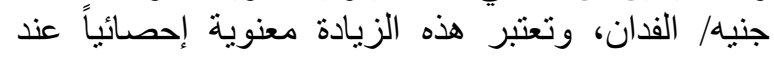

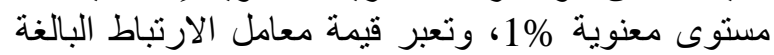

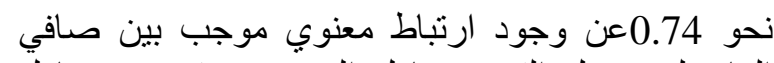

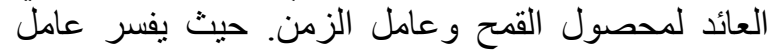
الزمن نحو \% 55 من إجمالي التغير ات في صناف صافي العائد

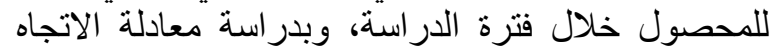

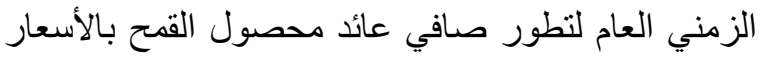

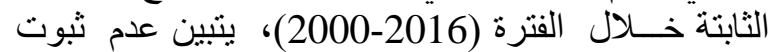
المعنوية الإحصائية لنطور صافى العائد حيث إنه بتين بتصف بالثبات النسبي. 
جدول (2): معادلات الاتجاه الزمني العام لتطور أهم المؤشرات الإتتاجية والاقتصادية لمصصول القمح علي مستوي الجمهورية خلال

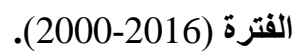

\begin{tabular}{|c|c|c|c|c|c|}
\hline المعنوية & $R^{2}$ & $R$ & المعادلة & 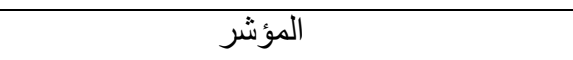 & رقم \\
\hline 0.93 & 0.87 & 0.93 & $\hat{Y}_{i}=\underset{(34.78)^{* * *}}{2.329}+\underset{(10.40)^{* *}}{0.067} X_{i}$ & المساحة بالمليون فدان & 1 \\
\hline 0.9 & 0.82 & 0.9 & $\hat{Y}_{i}=\underset{(25.77)^{* * *}}{41.366}+\underset{(8.42)^{* * *}}{1.32} X_{i}$ & إنتاج المحصول الرئيسي بالمليون إردب & 2 \\
\hline 0.94 & 0.88 & 0.94 & $\hat{Y}_{i}=\underset{(1.99)^{-}}{44.39}+\underset{(10.80)^{* * *}}{23.46} X_{i}$ & السعر المزرعي جنيه/ إردب بالأسعار الجارية & 3 \\
\hline 0.8 & 0.64 & 0.8 & $\hat{Y}_{i}=\underset{(8.22)^{* * *}}{88.17}+\underset{(5.45)^{* * *}}{5.49} X_{i}$ & السعر المزرعي جنيه/ إردب بالأسعار الثابتة & 4 \\
\hline 0.96 & 0.93 & 0.96 & $\hat{Y}_{i}=\underset{(1.65)^{-}}{388}+\underset{(14.08)^{* *}}{323} X_{i}$ & التكاليف الكلية بالجنيه بالأسعار الجارية & 5 \\
\hline 0.91 & 0.83 & 0.91 & $\hat{Y}_{i}=\underbrace{1109}_{(12.76)^{* *}}+\underset{(8.72)^{* *}}{73.91} X_{i}$ & التكاليف الكلية بالجنيه بالأسعار الثابتة & 6 \\
\hline 0.94 & 0.9 & 0.94 & $\hat{Y}_{i}=\underset{(2.83)^{* *}}{1929} .05+\underset{(11.64)^{* * *}}{518.16} X_{i}$ & الإيراد الكلي بالجنيه بالأسعار الجارية & 7 \\
\hline 0.78 & 0.62 & 0.78 & $\hat{Y}_{i}=\underset{(10.06)^{* * *}}{2261}+\underset{(4.94)^{* * *}}{108.48} X_{i}$ & الإيراد الكلي بالجنيه بالأسعار الثابتة & 8 \\
\hline 0.74 & 0.55 & 0.74 & $\hat{Y}_{i}=\underset{(1.62)^{-}}{779.12}+\underset{(4.31)^{*+1}}{202.33} X_{i}$ & صافي العائد بالجنيه بالأسعار الجارية & 9 \\
\hline
\end{tabular}

المصدر: حسبت من بيانات جدول (1).

جدول (3): تحليل التباين لاختبار أثر كل من المحافظات والزمن على الإتتاجية القدانية لمحصول القمح خلال الفترة ( 2016-2014).

\begin{tabular}{|c|c|c|c|c|}
\hline F المعنوية & $\begin{array}{c}\text { متوسط مجوع المربعات } \\
\text { (M.S) }\end{array}$ & 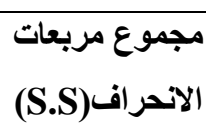 & درجات الحرية (D.F) & مصدر الاختلاف \\
\hline$* * 56.398$ & 32.48 & 844.53 & 26 & أثز المحافظات \\
\hline \multirow[t]{3}{*}{-1.83} & 1.05 & 2.1 & 2 & أثر الزمن \\
\hline & 0.57 & 29.49 & 52 & الخطأ \\
\hline & & 876.59 & 80 & المجموع الكلي \\
\hline
\end{tabular}

المصدر : وزارة الزر اعة واستصلاح الأراضي، قطاع الثئون الاقتصادية، نشرة الإحصاءات الزر اعية، أعداد مختلفة. 
متوسط الإنتاجية الرتبة السادسـة عن الخامسـة بنحو 1.58

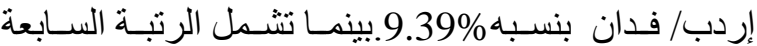
محافظة مرسي مطروح حيث بلـغ منوسط الإنتاجية نحو

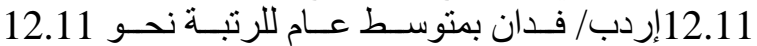

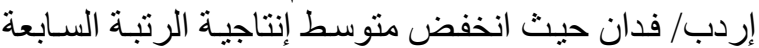

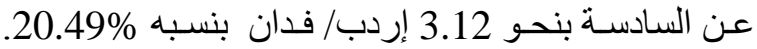

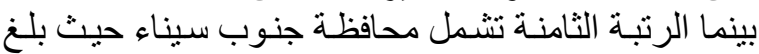

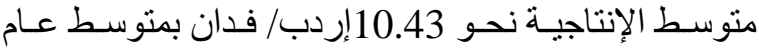

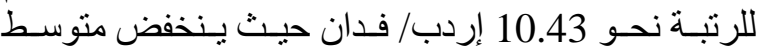

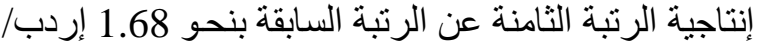

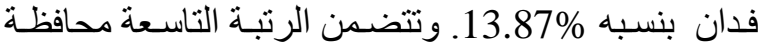

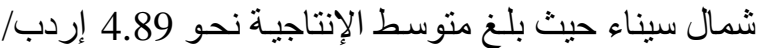

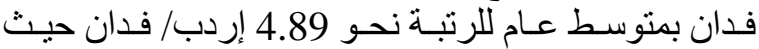

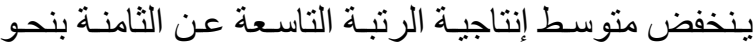
5.54 إردب/ فدان بنسبة 53.11 \%

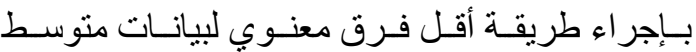

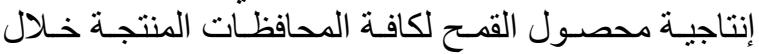

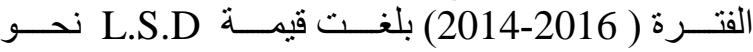
1.237، وبحساب الفرق بين منوسط الإنتاجية بين محافظة

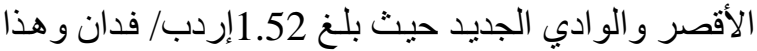

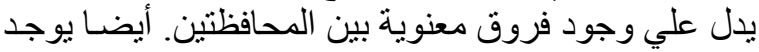

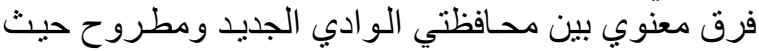

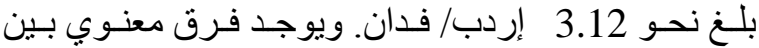

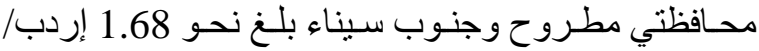

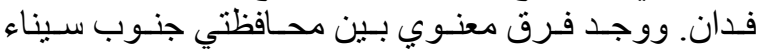

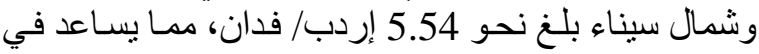
إعادة رسم الخريطة الإنتاجية لمحصول القمح على مستوى

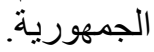

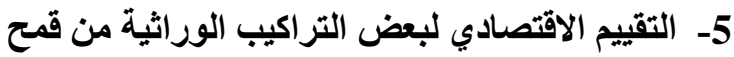

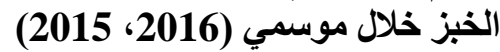

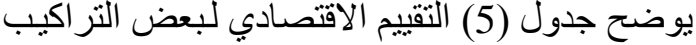

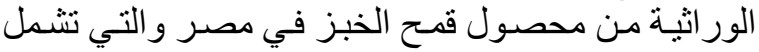

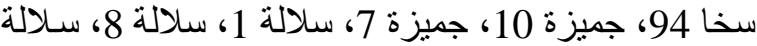
6، من حيث تأثثر ها على الإنتاجية الفدانية التكاليف الكلية و الإير اد الكلى و صافى العائد و عائد الجنيه المستثمر خلال

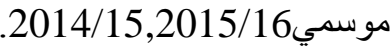
1-5 - الإنتاجية الفدانية

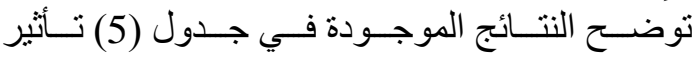

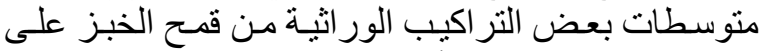

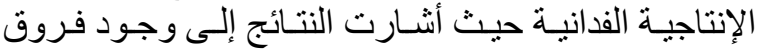

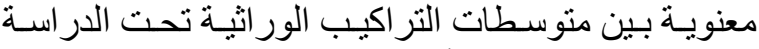

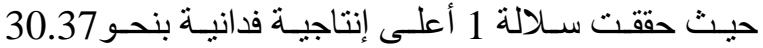

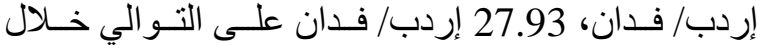

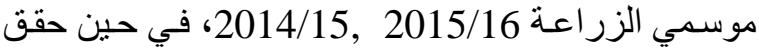

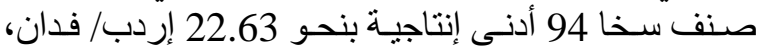

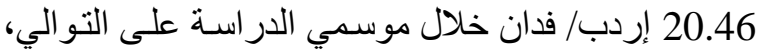

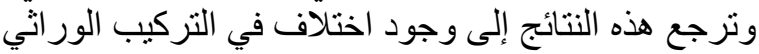

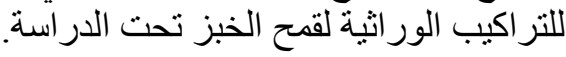
-2-5 الإيراد الكلي التي يشير جدول (5) إلى أنى أن التراكيب الوراثية من قمح
فرق معنوي في الإنتاجيات بين المحافظـات التي تقع في

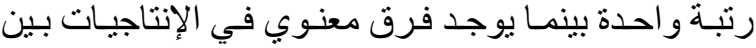

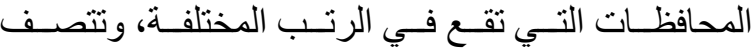
المحافظات الموجودة في الرتبة الأولي بأنها أعلي إنتاجية الرية

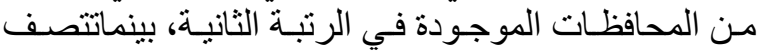

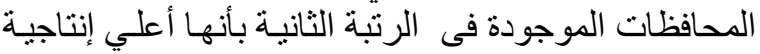

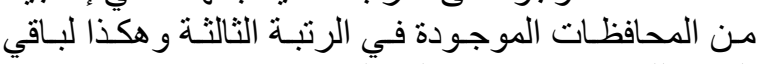
الرتب للمناطق الإنتاجية المختلفة. كذلك تضم الرتبة الر ابعة 7 محافظـات هي النوبة النوباريـة.

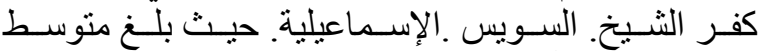

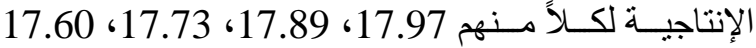

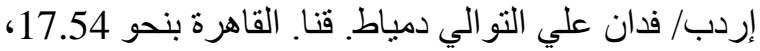

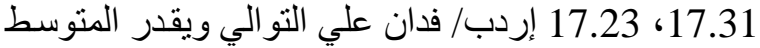

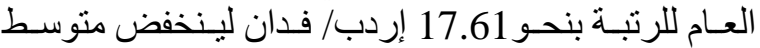
إنتاجية الرتبة الر ابعة عن الرتبة الثالثة بنحو 0.89 إلبنة إردب/ فدان بنسبة 4.81\%.

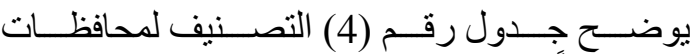

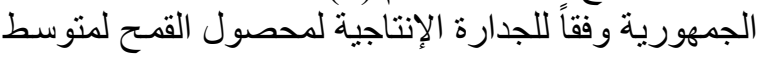

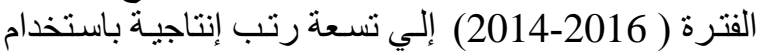

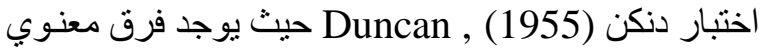

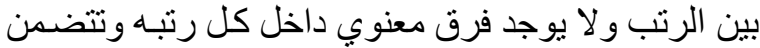

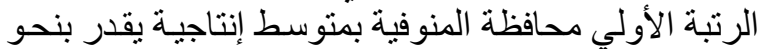
20.75 إردب/ فدان، ومحافظـة الجيزة بمتوسيط إنتاجيـة يقدر بنحو 20.23 إردب/ فدان بمتوسط عام للرتبة يقدر الربة

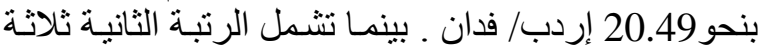

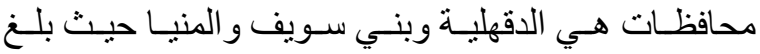

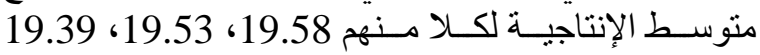

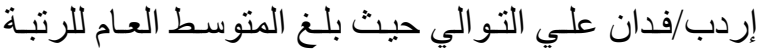

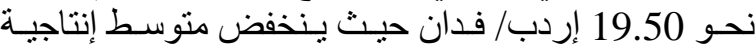

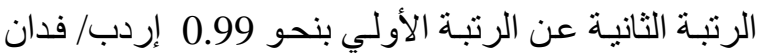

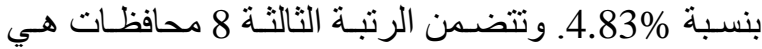

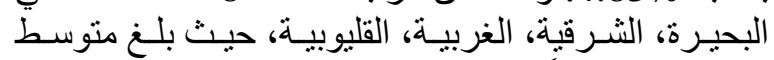

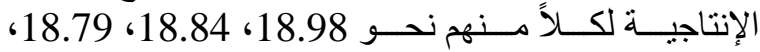

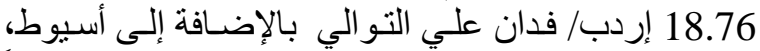

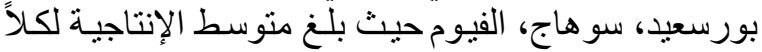

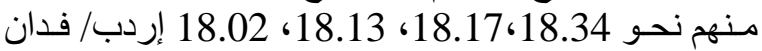

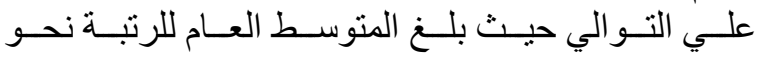
18.50إردب/ فدان لينخفض منوسط إنتاجيـة الرتبـة الثالثة

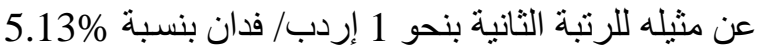

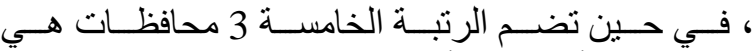
الإسكندرية. أسوان. الأقصر حيث بلـن متوسط الإنتاجيـة

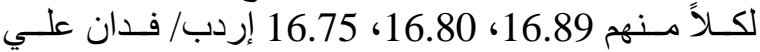

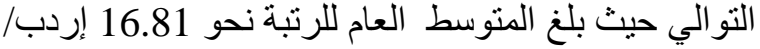

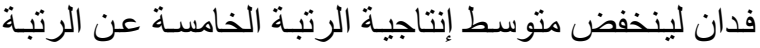

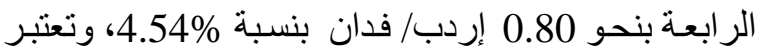

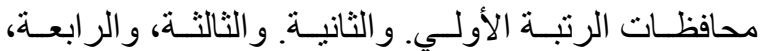
و الخامسة محافظات عالية الإنتاجية.

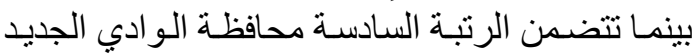

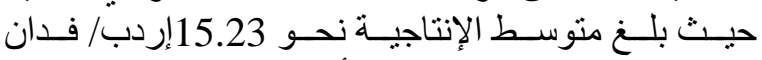
بمتوسط عام للرنبة نحو 15.23أردب/ فدان حيث ينخفض 
جدول (4): التصنيف الاقتصادي لمحصول القمح لمتوسط الفترة ( 2016-2014).

\begin{tabular}{|c|c|c|c|c|}
\hline المتوسط العام بالإردب/ فدان & متوسط الإنتاجية بالإردب/ فدان & عدد المحافظات & المحافظات & 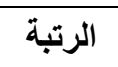 \\
\hline 20.49 & $\begin{array}{l}20.75 \\
20.23\end{array}$ & 2 & الجيزة & 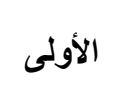 \\
\hline 19.50 & $\begin{array}{l}19.58 \\
19.53 \\
19.39\end{array}$ & 3 & بني سويف الدقلية & الثانية الثية \\
\hline 18.50 & $\begin{array}{l}18.98 \\
18.84 \\
18.79 \\
18.76 \\
18.34 \\
18.17 \\
18.13 \\
18.02 \\
\end{array}$ & 8 & 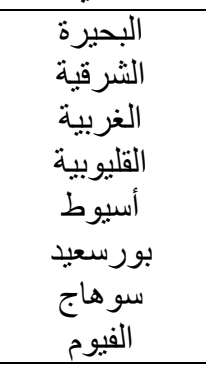 & الثالثة الثة \\
\hline 17.61 & $\begin{array}{l}17.97 \\
17.89 \\
17.73 \\
17.60 \\
17.54 \\
17.31 \\
17.23 \\
\end{array}$ & 7 & الكفر الثشيخ الإسماعية & الرابعة \\
\hline 16.81 & $\begin{array}{l}16.89 \\
16.80 \\
16.75\end{array}$ & 3 & الأسواندرية & الخامسة \\
\hline 15.23 & 15.23 & 1 & الو ادي الجديد & السادسة \\
\hline 12.11 & 12.11 & 1 & مرسي مطروح & السابعة \\
\hline 10.43 & 10.43 & 1 & جنوب سيناء & الثامنة \\
\hline 4.89 & 4.89 & 1 & شمال سيناء & التاسعة \\
\hline
\end{tabular}

L.S.D $=1.237$

صافي عائد بنحو9.06 ألف جنيه ، 7.88 ألف جنيه على في الف

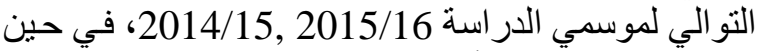

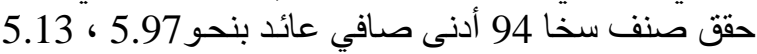

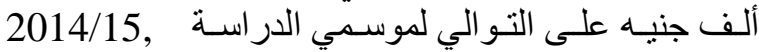
.2015/16

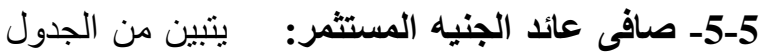

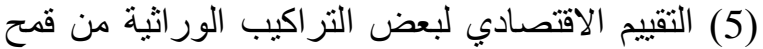

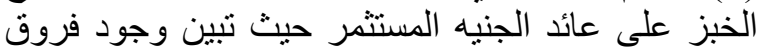
معنوية بين منوسطات الأصناف، وأن سلالة التهن 1 حققت أعلى عائد للجنيه بنحو 2.61، 2.015، 2.25 على التواف الي خلافل

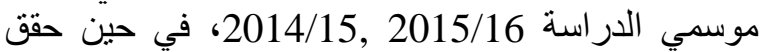
صنف سخا 94 أدنى عائد للجنيه بنحو 16/16 1.78، 1.52 على في سلى

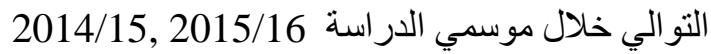
6- التقييم الاقتصادي لمعدلات التقاوي لبعض الترلئ الصناف

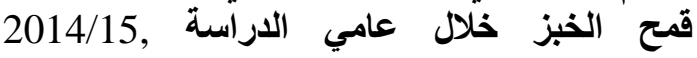
.2015/16 يوضـح جدول (6) التقبيم الاقتصـادي لأهـ معدلات التقاوي لبعض التر اكيب الور اثية مـن محصول قمـح الخبز لأني
الخبز أثرت معنويا على الإير اد الكلي حيث حققت سـلالة أنها

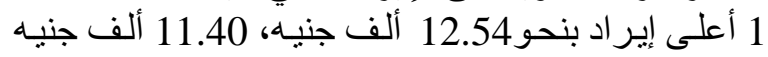

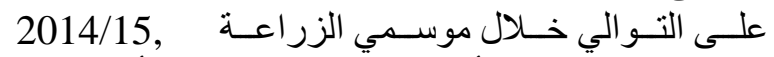

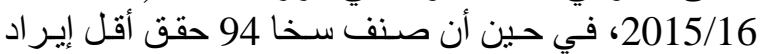
بنحو 9.35 ألف جنيه، 8.51 ألف جنيه على التو الي خـلال موسمي الدر اسة 3. 2014/15, 2015/16.

5- 3- التكاليف الكلية

يشير جدول (5) إلى تأثير بعض التئر اكيب الور اثيـة

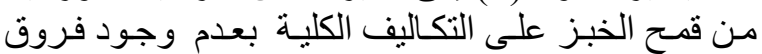

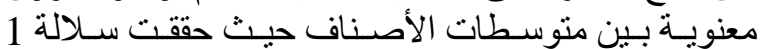

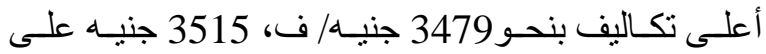

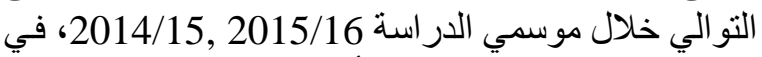

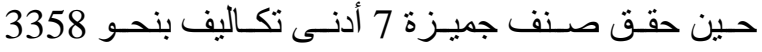
جنيه/ف خلال موسم الزر اعة 2014/2015، ونحو 3356

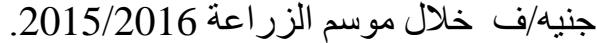
4-5 صافي العائد

يتبين من جدول(5) معنويـة تأثير التر اكيب الور اثيـة من قمح الخبز على صافى العائد وأن سلالة 1 حققت أعلى التى 


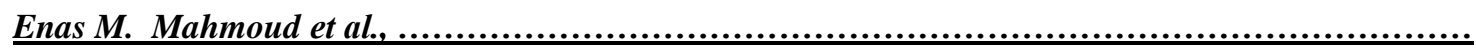

جدول (5): معالم التقييم الاقتصادي لبعض الأصناف لقمح الخبز خلال موسمي 2014/15, 2015/16.

\begin{tabular}{|c|c|c|c|c|c|}
\hline صافى عائد الجنيه & جنيه/ فذافي العائد & جنيه/ فلتان & جنيه/ فدان & إردب/ فدان & التراكيب الوراثية \\
\hline \multicolumn{6}{|c|}{$2014 / 2015$} \\
\hline 1.78 & 5978 & 3368 & 9346 & 22.63 & سخا 94 \\
\hline 1.91 & 6498 & 3396 & 9894 & 23.95 & جميزة 10 \\
\hline 1.84 & 6153 & 3358 & 9510 & 23.02 & جميزة 7 \\
\hline 2.61 & 9064 & 3479 & 12543 & 30.37 & سلالة 1 \\
\hline 2.05 & 7017 & 3416 & 10433 & 25.26 & سلالة 8 \\
\hline 2.32 & 7999 & 3456 & 11456 & 27.73 & سلالة 6 \\
\hline 0.086 & 296.4 & N.S & 296.4 & 0.717 & L.S.D (0.05) \\
\hline \multicolumn{6}{|c|}{$2015 / 2016$} \\
\hline 1.52 & 5127 & 3384 & 8512 & 20.46 & سخا 94 \\
\hline 1.84 & 6307 & 3428 & 9735 & 23.4 & جميزة 10 \\
\hline 1.62 & 5418 & 3356 & 8774 & 21.09 & جميزة 7 \\
\hline 2.25 & 7883 & 3515 & 11398 & 27.39 & سلالة 1 \\
\hline 1.76 & 5984 & 3412 & 9396 & 22.59 & سلالة 8 \\
\hline 1.99 & 6828 & 3437 & 10265 & 24.68 & سلالة 6 \\
\hline 0.075 & 252.5 & N.S & 252.5 & 0.607 & L.S.D (0.05) \\
\hline
\end{tabular}

الخبز تحت الدر اسة على التكاليف الكلية حيث حققت كمية الخية

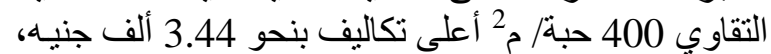

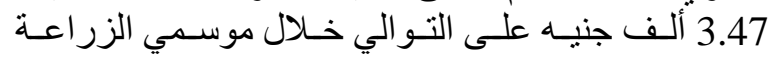

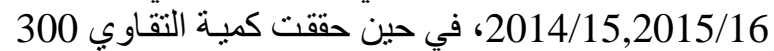

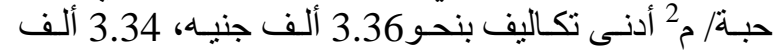
جنيه على التو الي خلال موسمي نيف:2014/15,2015/16.

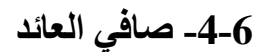

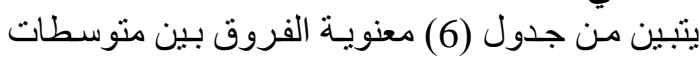

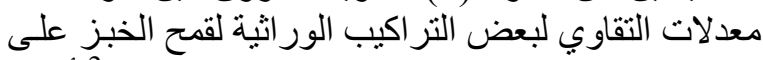

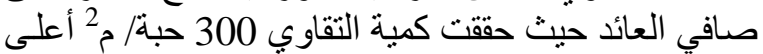
صافي عائد بنحو 7.97 ألف جنيه، الفيه،

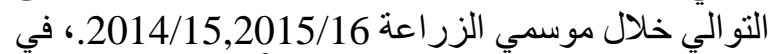

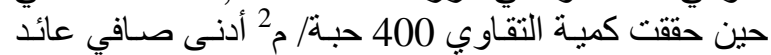

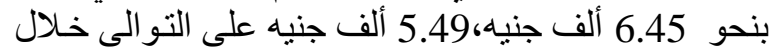
موسمي 2014/15,2015/16.

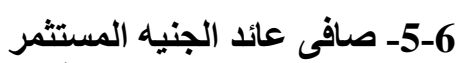

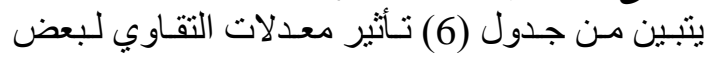

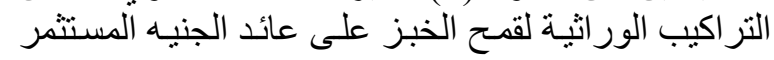

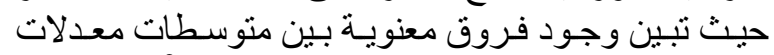

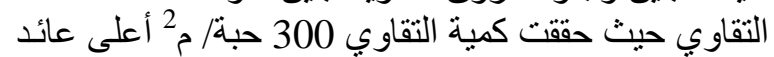

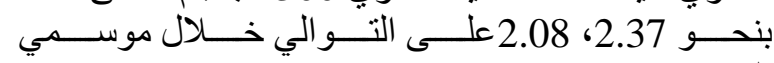

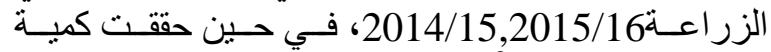

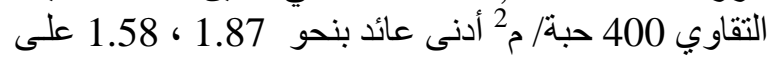

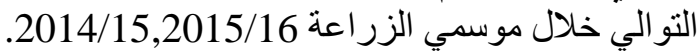

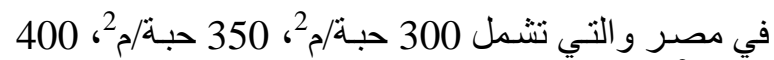

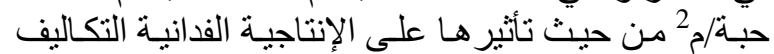

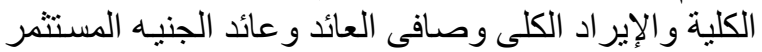
خلال الدراسة 2014/15, 2015/16.

\section{1-6- الإنتاجية الفدانية}

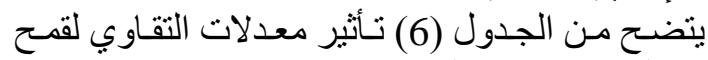

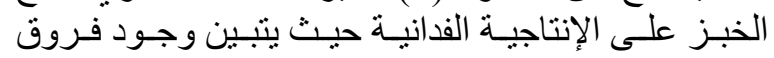

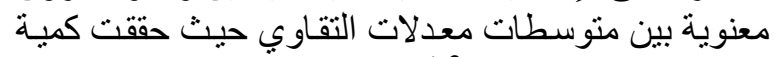

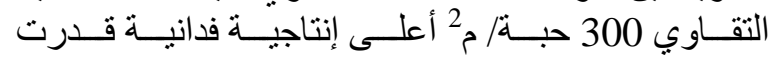

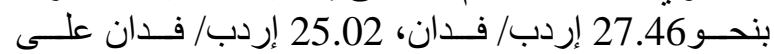

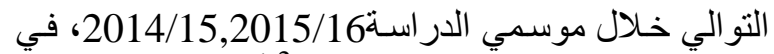

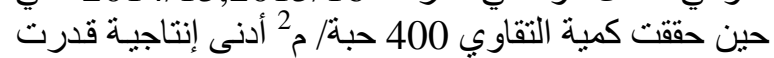
بنحو23.96 إردب/ فدان،21.57 إردب/ فدان إن على التو الي

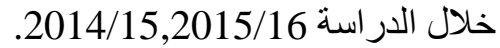

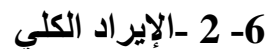
يثير جدول (6) تأثنير معدلات التقاوي لقمـح الخبز

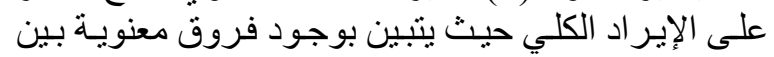

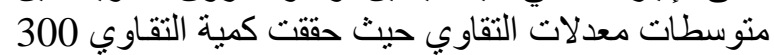

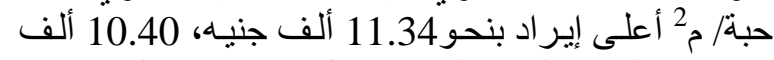

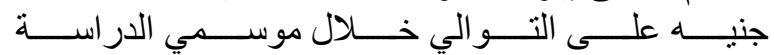
2014/15,2015/16، في حين حققت كمية التقاوي الني 400 حبة/ م2 أدنى إير اد بنحو 9.89 ألف جنيه، 8.97 ألف جنيه النيه

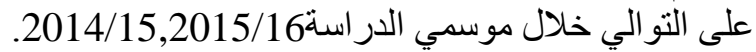
3-6 -6 التكاليف الكلية

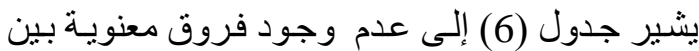

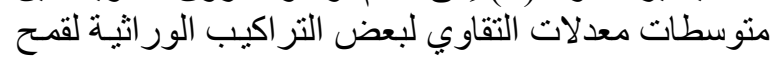


جدول (6): معالم التقييم الاقتصادي لمعدلات التقاوي لمحصول قمح الخبز خلال موسمي الدراسة 2014/15, 2015/16.

\begin{tabular}{|c|c|c|c|c|c|}
\hline صافى عائد الجنيه & صنيه/ فنى العائد & جنيه/ فذان & جنيه/ فلإنان & إردب/ الإتتاجية فذان & معدل التقاوي \\
\hline \multicolumn{6}{|c|}{$2014 / 2015$} \\
\hline 2.37 & 7976 & 3367 & 11342 & 27.46 & 300 حبة/ م2 \\
\hline 2.02 & 6962 & 3426 & 10352 & 25.06 & 350 حبة/ م2 \\
\hline 1.87 & 6452 & 3445 & 9896 & 23.96 & 400 حبة/ م2 \\
\hline 0.05 & 173 & N.S & 173 & 0.42 & L.S.D $(0.05)$ \\
\hline \multicolumn{6}{|c|}{$2015 / 2016$} \\
\hline 2.08 & 7038 & 3371 & 10409 & 25.02 & 300 حبة/2 \\
\hline 1.82 & 6237 & 3422 & 9659 & 23.22 & 350 حبة/ م2 \\
\hline 1.58 & 5499 & 3473 & 8972 & 21.57 & 400 حبة/ م2 \\
\hline 0.07 & 259 & N.S & 259 & 0.62 & L.S.D $(0.05)$ \\
\hline
\end{tabular}

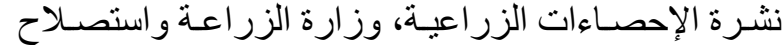

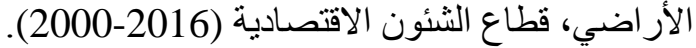

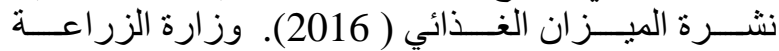
و واستصلاح الأر اضي، قطاع الثئون الاقتصادية.

Draper N.R. and Smith H. (1966). Applied regression analysis .John Willy and Sons .Inc; N.Y., USA, 397-402.

Duncan D.B. (1955). Multiple range and multiple F test. Biometrics. 11: 1-42.

Fisher R. A.(1948). Statistical Methods for Research Works. Oliver. London U. K.

Fujikoshi Y.(1993).Two-way ANOVA models with unbalanced data. Discrete Mathematics. 116:315-334.

\section{7- - 2003 المراجع}

الصو الحي، حمدي (2003). الإمكانيات الاقتصـادية لحل الدل

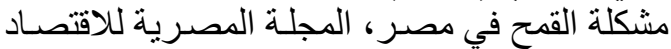

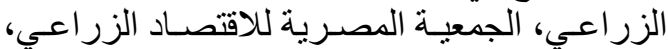

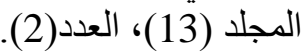
عبد الو هـاب عـادل محمد ، أحمد محمد حسن الحن (2018). در اسة اقتصادية تحليلية لتخفيض الفجوة القدحية في

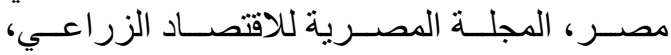

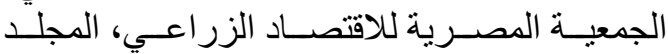
(28) (28) العدد(3)، سبتمبر.

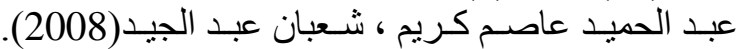

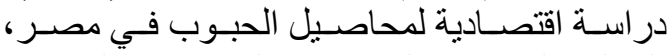

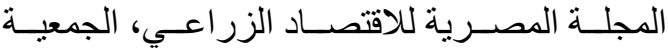

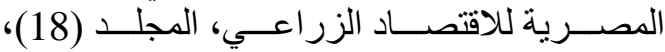
العدد(4)، ديسمبر.

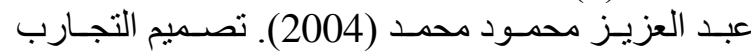

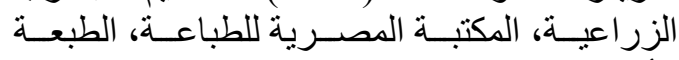
الأولى. 